\title{
Education as Mediation: Blurring the Line between Expert and Lay Knowledge
}

\author{
JACQUELINE MCINTOSH \\ Victoria University of Wellington, New Zealand \\ PHILIPPE CAMPAYS \\ Victoria University of Wellington, New Zealand \\ MAIBRITT PEDERSEN ZARI \\ Victoria University of Wellington, New Zealand \\ BRUNO MARQUES \\ Victoria University of Wellington, New Zealand
}

- ince the 1970s more than half of the Tokelau population has relocated to New Zealand due to limited natural resources and overcrowding of the $10 \mathrm{~km} 2$ land area.

This raises issues related to the cultural identity and wellbeing of Tokelau people in New Zealand. Local Tokelau community groups in the Wellington region seek to maintain their cultural traditions through the development of community centres. However, these facilities are expensive to purchase, build and to maintain, and have the potential to overburden the Tokelau community, which has a very high portion of low-income people. This paper discusses a series of initiatives the School of Architecture at Victoria University of Wellington has initiated in relationship with Te Umiumiga a Tokelau Hutt Valley community to assist the development of a sustainable cultural community centre complex. It elaborates upon the processes of empowerment and on-going developments that have resulted in significant benefits for the community, students and staff alike. Ways that the university can work as a mediator between institutions such as museums, local city councils, funding organisations and disadvantaged/underprivileged communities are explored. A key finding of the collaboration showed that mediation goes both ways and that there is both a process of giving and receiving in such a relationship that facilitates a blurring of boundaries between 'expert' and 'lay' knowledge. Through various avenues, students have been empowered to engage directly with the community, enabling the redesign of the Youth Centre, construction of furniture, exploration of alternative energy sources, community garden initiatives, and looking at landscape as a resilient resource. Empowering outcomes for the community have extended well beyond arts and craft demonstrations to encompass anti-violence campaigning, new parent campaigns, the celebration of children's books in the Tokelau language, youth talent competitions, and elder games. By participating in the learning community, students and faculty developed critical and creative skill and worked together for more complex understandings of the world.

\section{INTRODUCTION}

Tokelau, one of the world's smallest and most remote countries is made up of three tiny atolls in the Pacific Ocean (Figure 1). Climate change has resulted in ongoing depopulation and today more than 75\% of Tokelau people have relocated to New Zealand. Seeking to maintain their traditions in the face of strong social and economic pressure to assimilate in the culture of their host country (New Zealand), the community has deployed a number of strategies. This paper discusses a series of collaborations between the Tokelau community and the School of Architecture using participatory design methods.

The research was initially developed at the instigation of the Tokelau community, primarily from the Nokunonu atoll, which had relocated to the Hutt Valley in the Wellington region. The local Tokelau leaders sought to revitalise their community through promoting the idea that developing a built centre would support the on-going wellbeing of their cultural heritage.

Initial conversations between the community and the School of Architecture identified a desire for not just a community hall, but also a community centre that 'captured the essence of a Tokelau village'. This was a challenge that solicited the interest of a group of architecture lecturers with research agendas in 


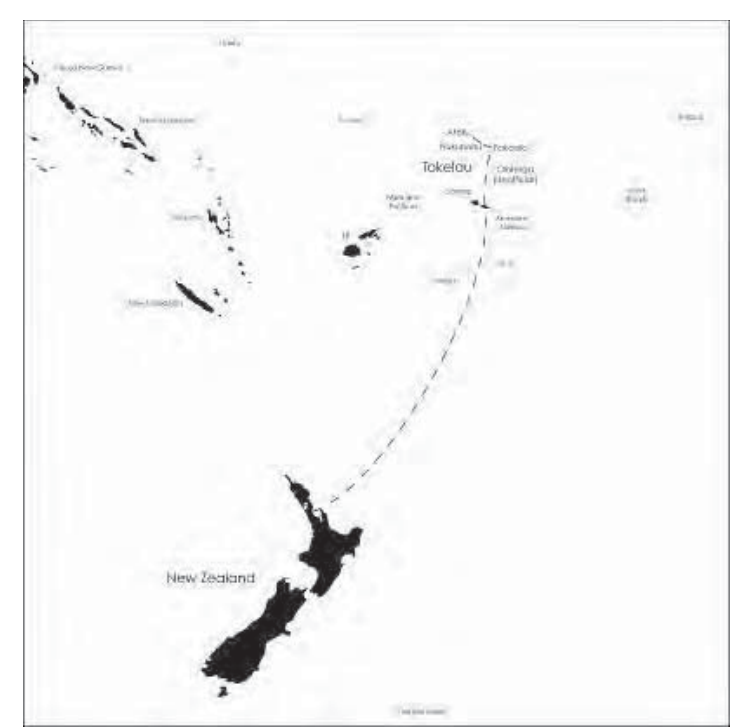

Figure 1. Map of Tokelau relative to New Zealand.

Developing Collaborative Relationships

participatory design, sustainable architecture, social wellbeing, collective memory and the use of real life projects to educate their students.

Lacking detailed knowledge of Tokelau's history and culture, as well as the absence of any students who may have been able to help facilitate the cultural relationship* between the University and the Community, required employing a method of participatory design. This allowed the community to design with and through students. This strategy was also believed to be well suited to the Tokelau community's desire for engaging in community building processes. From the University's perspective the relationship provided the means to train its students as professionals of the built environment by working with real clients, while preparing students to be socially responsible world citizens. To undertake such a process where the Tokelau people became comfortable enough to participate, to debate and to design and not just accept what the papalagi expert provided required a great deal of trust and cooperation.

The School of Architecture research team involved in the project to date has been made up of five academic staff, five postgraduate students, and more than one hundred undergraduate students across the disciplines of architecture, sustainable engineering, project management, interior architecture and landscape architecture. As academic staff designed and implemented various learning experiences for different cohorts of students in relation to the Tokelau Community Centre, they met to clarify pedagogical commonalities and differences. Approaches to the project were grounded in critical pedagogy (Morrow, $2007^{1}$ Harriss and Widder, 2014²), social learning theories (Schon 1983³, Bruffee, 19994), and constructive developmental theories (Baxter Magolda, 19995 , Kegan, 19946).

\section{INDUCED PARTICIPATORY DESIGN AND LIVE PROJECTS}

Participation in decisions that determine the quality and direction of built environments requires the involvement of the community, giving primacy to their rights to participate in the shaping of the world in which they live (Sanoff, 1990) ${ }^{7}$. However, designing in genuine partnership with those who will use the facilities requires that all parties get to know one another and build mutual respect. There is an ethical stand underlying participatory design that recognises an accountability of design to the world it creates and the lives of those who inhabit it. Morrow

Figure 2. Diagram of the leveraged opportunities using a participatory design framework to build relationships between community, university, museum, municipality and individuals

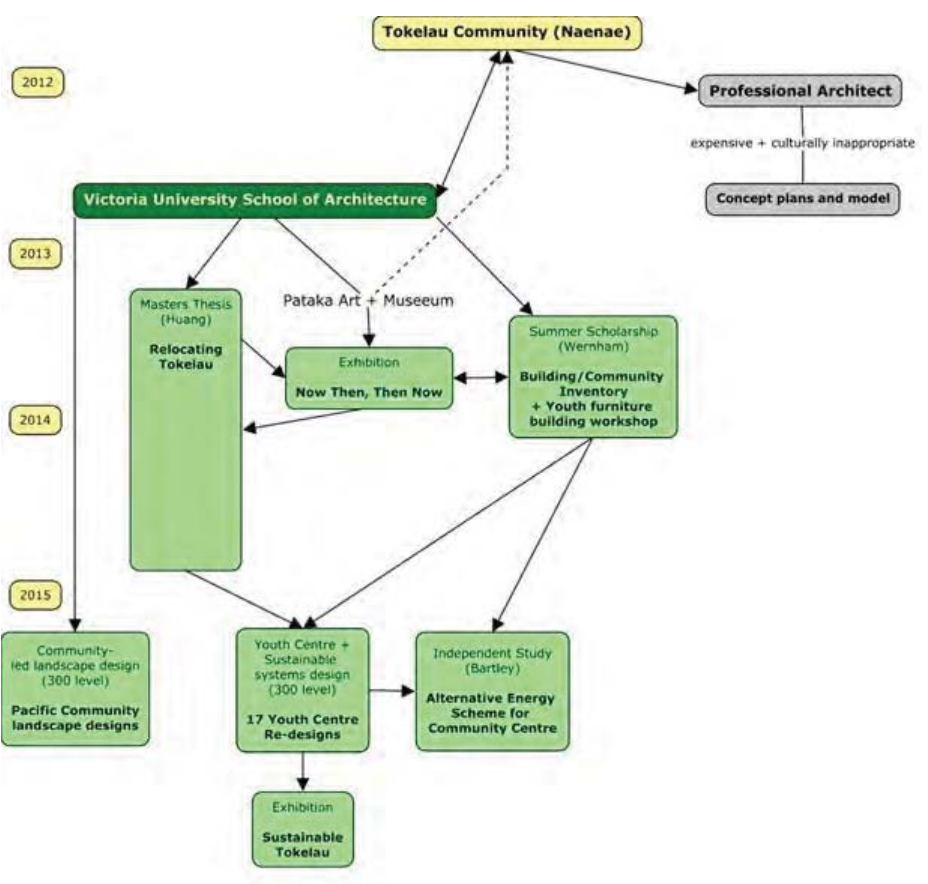

* Seeking to find an architecture student of Tokelau descent in the School of Architecture proved difficult and is consistent with an under representation of Tokelau (and Pacific Island) students in the University overall. Introducing university students to the Tokelau youth allowed a beneficial exchange of cultural information. 


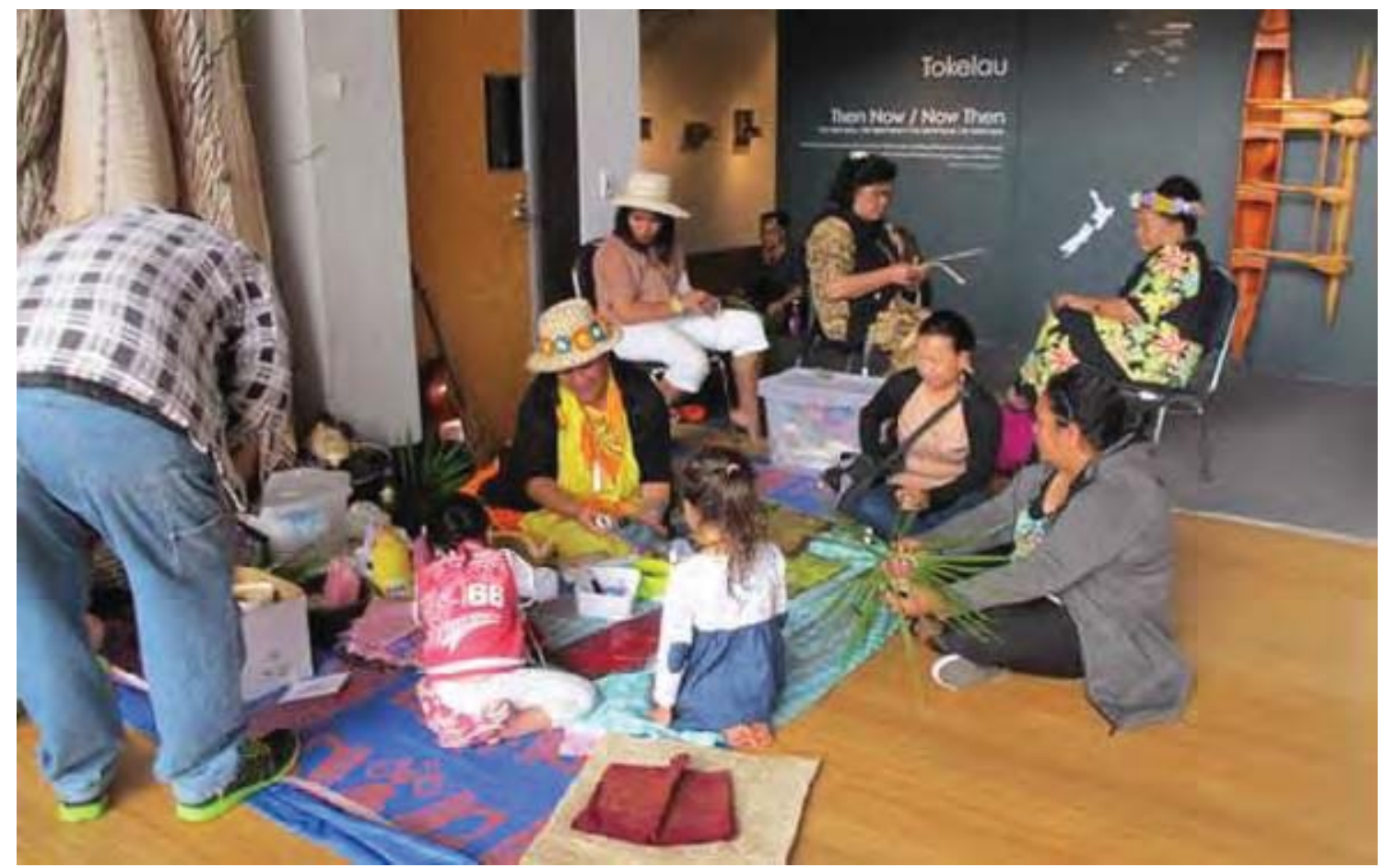

Figure 3. Exhibition entrance.

$(2007)^{8}$ discusses the importance of forming partnerships with local communities as a way to expand architectural education opportunities and also benefit communities through civic involvement by students. Live projects are those that engage real citizens in real-time contexts, and encourage students to become active citizens of a community dedicated to cultural and ecological health.

\section{A SERIES OF ENGAGEMENTS}

As previously mentioned, various approaches were undertaken by different staff and students in engaging with the community. From these exercises, a new model of vertical and interdisciplinary integration of students and research activities with real clients in a university context is proposed (Figure 2).

\section{Connecting with the University: Summer Scholarship Programme}

In the summer of 2013, the Tokelau Community Association co-funds a Summer Scholarship project with the University to provide a student scholarship devoted to undertake research in the area of suitable participatory design methods, as well as a full review of all of the resources that existed in the community to develop their 'village'. The physical inventory consisted of an assessment of the buildings on the site, as well as their components to determine opportunities for re-use (Wernham,
2014) ${ }^{9}$. The human inventory identified the individual community members, committees they were involved with, the things they were good at, and the things that they enjoyed doing. The main objective was to gather information, to introduce the participants from both the Community and the University, and to understand roles, resources, and limitations. It also served to establish a set of realistic expectations for all involved.

2. Creating public awareness through exhibition In collaboration with the Tokelau community, McIntosh and Campays curated an exhibition entitled 'Tokelau: Then Now, Now Then' which was held at Pataka Art + Museum, in Porirua, New Zealand during the Arts Festival, between 21 February and 13 April 2014 (Figure 3). The exhibition title embodied the meaning behind the exhibition's intentions and its content which included historical photography and geographical information, traditional Tokelau artefacts, stories and interactive games in both Tokelau and English, as well as current images of community members and local scenes. The focus on climate change and Tokelau, predicted to be one of the first of the Pacific Islands to be inundated by sea level rise (Connell, $2015)^{10}$, was not only about the future of the atolls, but also of the Tokelau diaspora, who continue to be displaced due to climate change (Connell, 2015) ${ }^{11}$. 


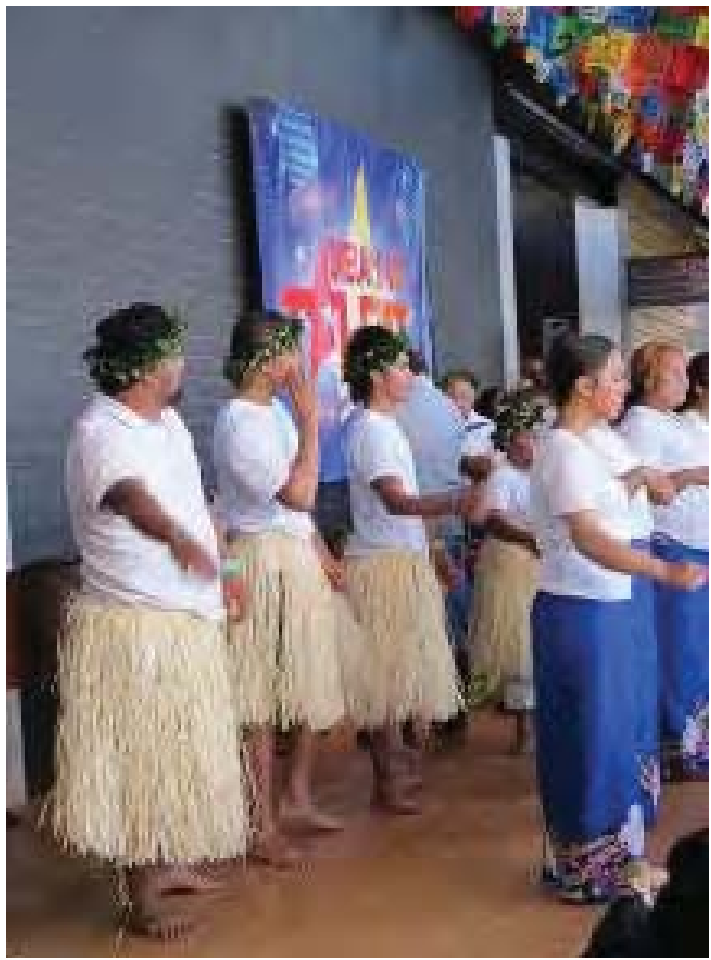

Figure 4. Youth talent contest.

With New Zealand being the principal residence for Tokelau people, the exhibition raised the question of cultural and societal insertion within a foreign land and culture, and challenged desires and visions for the future.

The perception and experience of the exhibition, the engagement with traditions in the new context of New Zealand, community empowerment, and constructive reflection regarding the exhibition are discussed comprehensively in McIntosh, Campays and Chicca, $2015^{12}$.

\section{Empowering the Community}

The exhibition proved to empower the entire Tokelau community from the Wellington region. The local Mayor and a Member of Parliament, who could both claim either direct Tokelau heritage or connection, opened the event. When the museum space proved to be too small for further activities associated with the exhibition, a 'Tokelau Day' was held in the general foyer and the central open spine of the museum. During the day, the community showcased traditional dancing, music, singing, traditional food, children's games, and sold native handicrafts. A version of a popular talent competition entitled Tokelau's got Talent (Figure 4) was organised by the youth bringing performing groups together in a celebration of local culture. This also served to bring

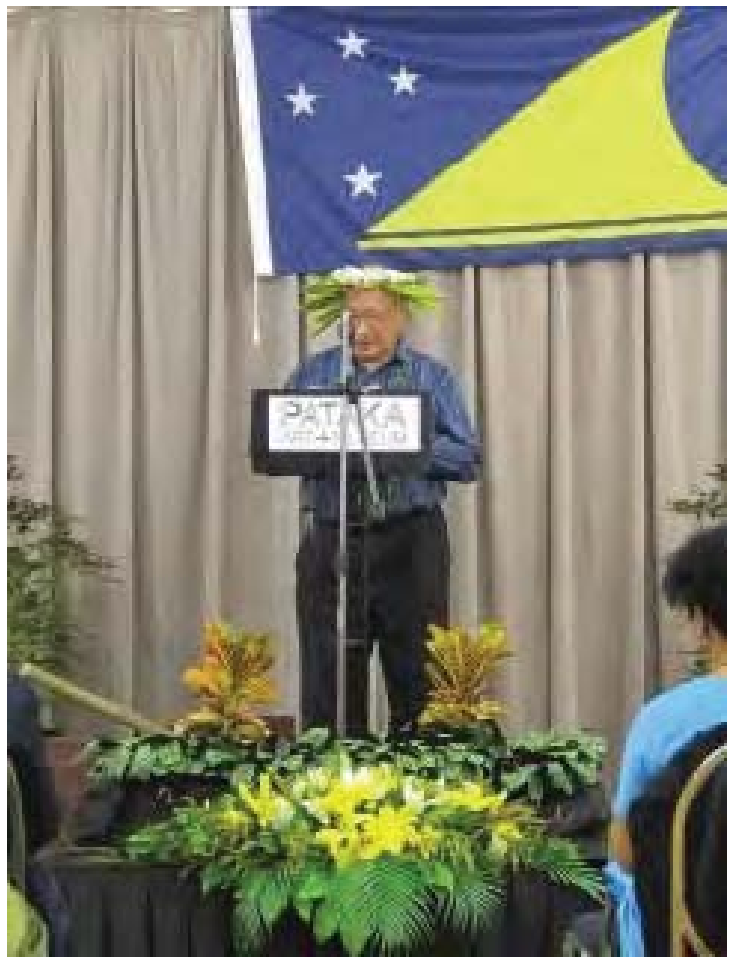

Figure 5. Anti-violence book launch.

younger people into the museum, a place which they might not normally frequent.

Finally, under the auspices of the 'Strong Pacific Families' initiative formed by the New Zealand Ministry of Social Development, the 'Te Kaiga Maopoopo' committee was formed to address family violence. The committee used the Tokelau Day to launch a book putting forward a strategy for protection against family violence using Tokelau culture. The book launch brought many important representatives of government and powerful politicians together with significant members of the community (Figure 5). This in turn created an awareness of the Hutt Valley community centre/village project, which proved useful and advantageous for future events and plans.

\section{Engaging with the youth:Youth Centre vision} and furniture making

Youth disenchantment had already led to the community designating one of the warehouse buildings as a 'Youth Centre'. Funding was obtained to decorate the industrial building to make it more attractive; however, the space remained uncomfortable, lacking windows, heating, adequate lighting, furnishings, and importantly a sense of human scale.

To start to address this situation, the youth leaders 


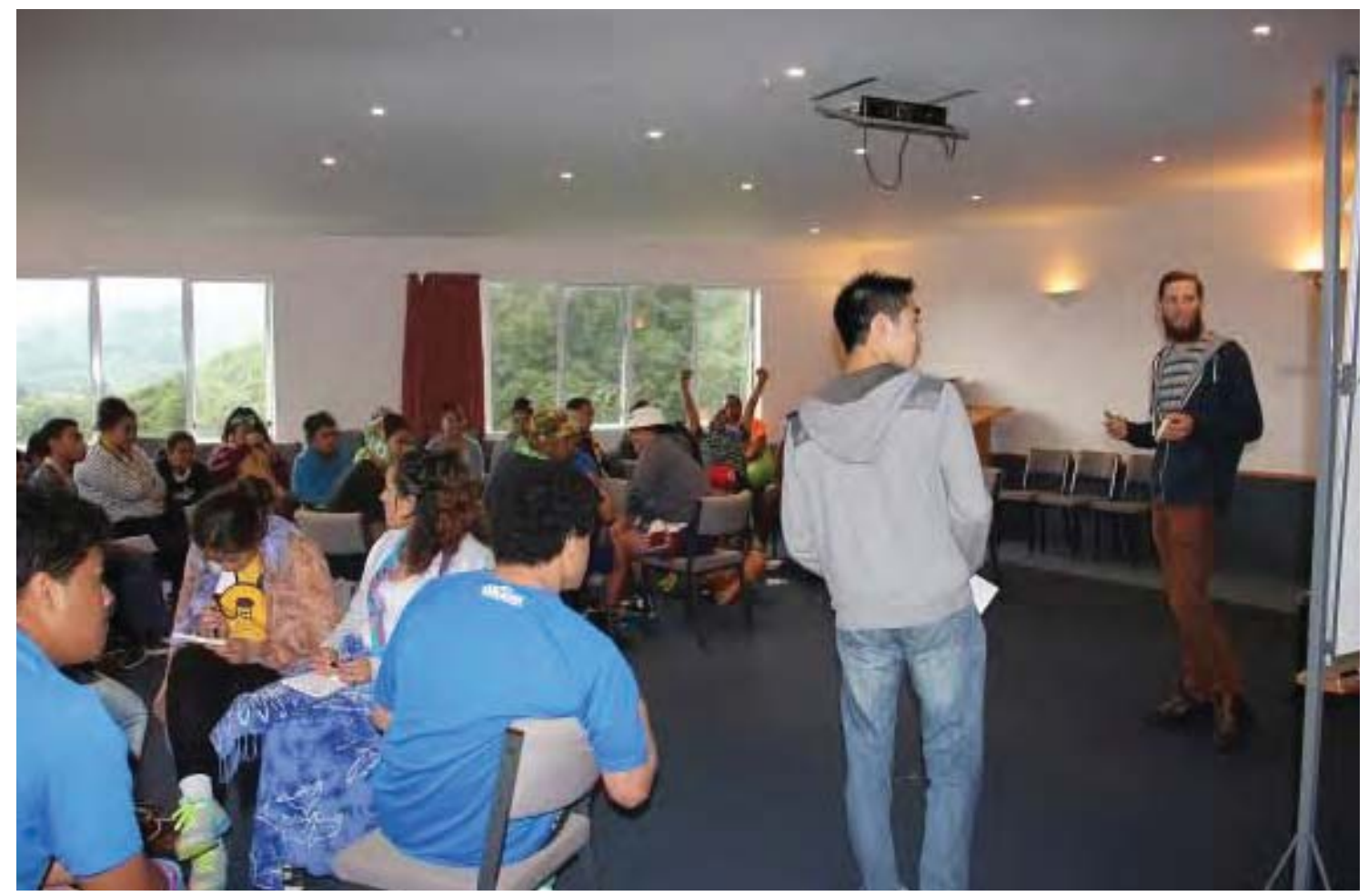

Figure 6. Participatory Planning Workshop with the Tokelau Youth.

invited a team from the School of Architecture to their annual Tokelau Retreat for the Hutt Valley Youth Community (Figure 6). One of the Masters students introduced a collaborative participatory design exercise to capture ideas, desires, and aspirations of the youth.

This activity achieved two key objectives. First, the youth formed a collective vision of a desirable future for the Community Centre. Second, they committed to a series of on-going direct engagement projects. The first project selected for implementation was the construction of moveable furnishings made achievable and affordable by sourcing suitable building materials such as wood pallets.

The youth fabricated furniture out of cardboard to determine the size, layout, and number of items that would best suit their vision. Masters students in turn, designed furniture options for the youth that could provide social space. These designs were then constructed in a series of community workshops. A wide range of youth were engaged in building the Youth Centre furniture. Many adults and elders gathered to watch the activities. In preparation for the fabrication workshop, the youth collected a large number of pallets and borrowed tools and equipment. Empowered by their initial success, they continued on working independently from the Masters students and took on leadership roles themselves. The workshops led to a sense of pride as the youth showcased their accomplishments and invited elders to feel and experience their work (Figures 7-11).

The success of this strategy, first generating an overall vision then breaking it into achievable smaller targets, followed by the process of mock-up and fabrication was to be employed for the future engagement of the community.

\section{RE-IMAGINING AND REDESIGNING THE YOUTH CENTRE AS SUSTAINABLE ARCHITECTURE}

To build upon this work of engaging with the youth, a cohort of sixtysix third-year sustainable architecture students (made up of architecture, interior architecture, landscape architecture and building science students) worked in multidisciplinary groups to explore and innovatively redesign theYouth Centre and surrounding landscape while investigating sustainable systems such as water catchment, food growing, energy generation and waste mitigation. A multi-disciplinary approach to design is important because it potentially leads to greater sustainability outcomes but also has social benefits due to a more participatory and socially inclusive design methodology (Storey \& Pedersen Zari, 2006 $6^{13}$, Wahl \& Baxter, 2008 ${ }^{14}$ ). 

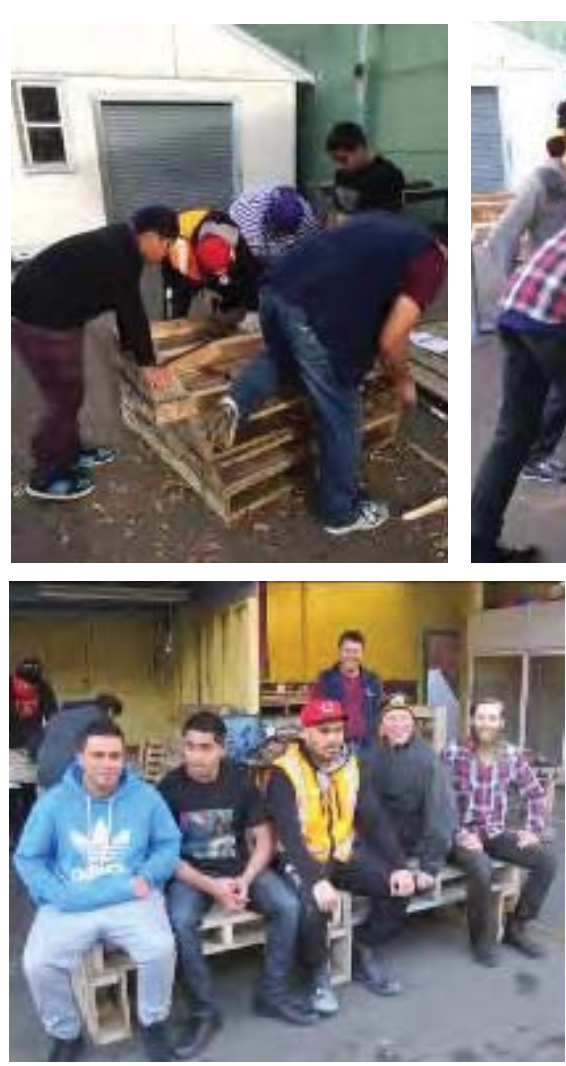
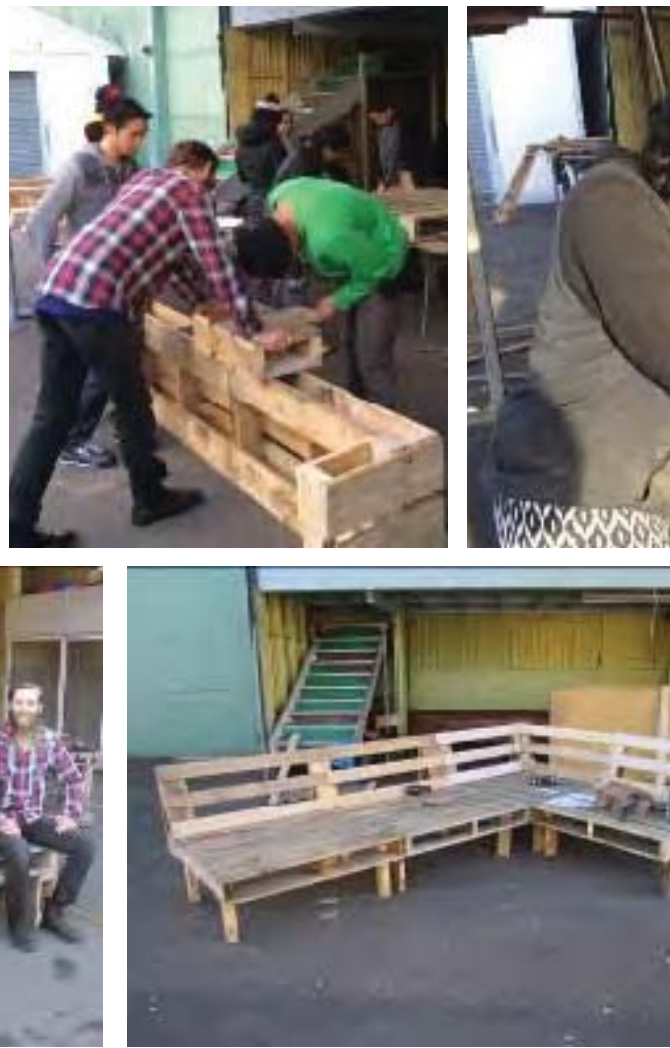

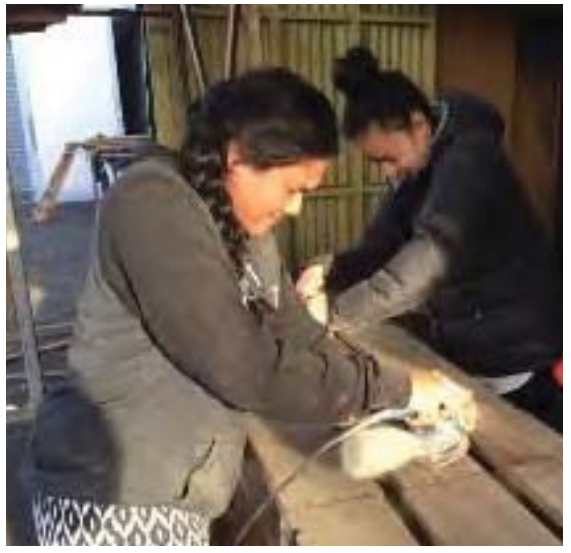

Clockwise from top left: Figure 7.

The demolition crew.

Figure 8.

The assembly crew.

Figure 9.

The finishing crew.

Figure 10.

The finished products.

Figure 11.

The finished products.
Much architectural education emphasises individual and competitive learning (Cortese, 2003) ${ }^{15}$. It is important therefore that students have a chance to work with other disciplines on complex problems in group situations (Pedersen Zari, 2009) ${ }^{16}$. Building on prior student work enabled consistency, a continuity of relationship and a passing on of knowledge and insights that can be difficult to achieve with student involvement in long-term projects.

The advantage of using the Tokelau Youth Centre as a live project for the sustainable architecture students was two-fold. First, the engagement with the Tokelau community facilitated learning about the impact of climate change in the Pacific region and comprehension that climate change is already affecting millions of people. One direct impact of climate change in New Zealand is the increased migration of people, particularly from Pacific Islands due to direct and indirect impacts of climate change. In order for students to meaningfully engage with an issue as large and global as climate change, action must begin locally and at a personal level. Putting knowledge gained in academia into action through live projects can be a positive and motivational way to learn more about environmental issues and is a critical feature of developing leadership skills (Cortese, 2003) ${ }^{17}$. As of 2012 Tokelau is also the world's first $100 \%$ solar-powered nation. This provided a further avenue for learning and a means to tie the Youth Centre redesign back to a Tokelau atolls context. An opportunity for students to practise initialising, or positive activism which puts tangible change into place, rather than protest activism which is typically based on fighting against something was also provided (Morrow, 2007) ${ }^{18}$.

Along with a developed community centre plan and seventeen redesigns of the Youth Centre, students collectively produced a large and comprehensive body of work. This included a fully developed solar power generation scheme for the Community Centre, full scale prototypes for movable community garden planter boxes, food production concepts and planting guides, several innovative rain water and storm water runoff retention and filtering systems, renewable energy schemes for the community, aquaculture systems, passive solar interventions to make the buildings more habitable and functional, greenhouse schemes, bike share programme proposals, a series of new furniture and fence designs made from reclaimed materials, composting and waste minimisation systems, dynamic façade systems, natural playground and 

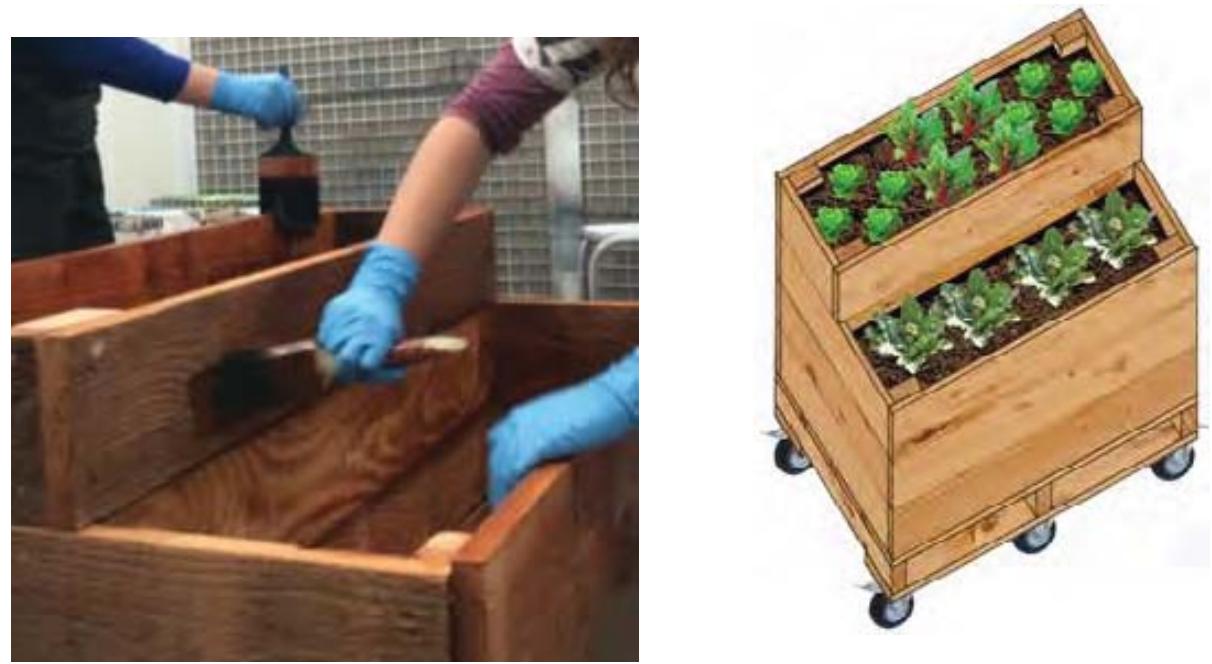

Figures 12 and 13. Students designing and building prototypes for the Youth Centre redesign.

recreational field concepts, social gathering and dialogue spaces reflecting Tokelau cultural concepts, and finally living walls and green roof designs. The projects enabled students to engage with Tokelau elders and youth and facilitated exchanges of knowledge and experience about Pacific culture but also about the University. The community engaged with the students to develop design ideas, but also to see ideas being developed into physical outcomes. Representatives of the community helped to review the work and an exhibition of the work was held at the School of Architecture before the work was taken back to the community for sharing and discussion.

\section{THE VALUE OF COMMUNITY-LED DESIGN}

Prevailing discourse emphasises the university's place as a paramount player in a global system increasingly driven by knowledge, information, and ideas (Clegg et al, 2013). ${ }^{19}$ Knowledge is becoming the main driver of economic growth, and education is increasingly becoming the foundation for individual prosperity and social mobility (Biesta, 2006). ${ }^{20}$ By focusing on the social, cultural, and cognitive bridges offered in specific courses of study, the Tokelau Community Centre project highlighted the strengths of a multicultural learning community approach. A bridge must be anchored on both sides, with as much respect for where it begins as for where it ends (Kegan, 1994) ${ }^{21}$. Student activities have the ability to act as a mediator between diverse worlds in the process of learning and exploring. On one side of the bridge lies the students' familiar home territory, including their family, work place, peers, and institutions (Beach, Lundell, \& Jung, 2002) ${ }^{22}$. On the other side is the territory of cultural communities, which are shaped by rules, traditions, discourse and values that may be very different from students' own understanding. To help students construct bonds between their own personal and cultural knowledge and that of another community, they had to be willing to learn from the communities' experiences and ways of knowing and behaving. Two aspects of community were considered. First, students from different courses, years and disciplines, formed a learning community in which members helped each other learn to research. By building upon prior student work and through supporting each other by listening, problem solving, and working together, students honed academic skills and explored ideas in ways that valued individual knowledge. Second, students were invited to use these academic skills to explore what it means to practice community: by working together as a group with a shared mission in order to better understand the nature of Tokelau. These two agendas supported and sustained each other.

\section{CONCLUSION}

The recognition of the need for early and meaningful engagement and collaboration with communities requires new research, methods and tools for understanding and supporting best practice. Local, national, and international frameworks have been developed to support this and sustain innovative educational approaches embedded in critical and creative thinking such as those defended by UNESCO through the World Declaration on Higher Education for the Twenty-first century, which states:

"In a world undergoing rapid changes, there is a perceived need for a new vision and paradigm 
of higher education, which should be studentoriented, calling in most countries for in-depth reforms and an open access policy so as to cater for evermore diversified categories of people, and of its contents, methods, practices and means of delivery, based on new types of links and partnerships with the community and with the broadest sectors of society" (UNESCO, 1998) ${ }^{23}$.

The diverse activities discussed in this paper gave students multiple opportunities to articulate their own understandings of culture in the framework of developing sustainability and resilience. Themes of identity, community, and agency arose from the work and instead of being isolated by difference,students were proposing that communities embrace interdependence. By constructing their own ways to integrate personal and cultural knowledge with the course content, students acted as creators of knowledge and partners with instructors rather than as passive consumers. There was often a heightened sense of vulnerability and uncertainty that was both exhilarating and problematic. This tension between cohesiveness and divisiveness is a problem common to many learning communities. For most students the community provided an anchor and a kind of accountability they might not have experienced if they were in a course without community connection.

Conceptualising student learning as a dynamic process of interactions between communities, histories, and contexts, replaces the view that equates agency with individual self-sufficiency. Instead, agency is viewed as a matter of participation, collaboration, and a shared sense of mission. There are many benefits to this approach, from improving civic participation and ensuring more democratic outcomes, to creating a strong sense of community and strengthening people's attachment to their place and to each other, producing more sustainable solutions.

1 Morrow, Ruth. "Creative Activism: a pedagogical and research tool." Enquiry: A Journal for Architectural Research 4, no. 12007.

2 Harris, Harriet and Lynette Widder Architecture Live Projects: Pedagogy and Practice, Routledge, London and New York, 2014

3 Schön, Donald A. The reflective practitioner: How professionals think in action. Vol. 5126. Basic books, 1983.

4 Bruffee, Kenneth A. Collaborative learning: Higher education, interdependence, and the authority of knowledge. Johns Hopkins University Press, 2715 North Charles Street, Baltimore, MD 21218-4363, 1999.

5 Magolda, Marcia B. Baxter. Creating contexts for learning and self-authorship: Constructive-developmental pedagogy. Vanderbilt University Press, 1999.

6 Kegan, Robert. In over our heads: The mental demands of modern life. Harvard University Press, 1994.

7 Sanoff, Henry (Ed.), Participatory design: theory and techniques, Raleigh, NC 1990.

8 Morrow, Ruth. "Creative Activism: a pedagogical and research tool." Enquiry: A Journal for Architectural Research 4, no. 12007.

9 Wernham-Doo, T (2014), Survey of Tokelau community complex, Naenae, Hutt City, New Zealand, unpublished report.

10 Connell, John. 'Pacific Diaspora' in Migration and Development: Perspectives from the small states, W, Khonje, W ed. Commonwealth Secretariat, London 2015

$11 \mathrm{ibid}$

12 McIntosh, Jacqueline, Philippe Campays and Dr. Fabricio Chicca. "Recreating Tokelau: Distilling the Essence of Place in a Community Center." In Cases on Grassroots Campaigns for Community Empowerment and Social Change, ed. Rebecca Nthogo Lekoko, 75-103 (2015), accessed July $02,2015$. doi: 10.4018/978-1-4666-8568-0.ch004

13 Storey, John. B., \& Maibritt Pedersen Zari, Factor X-Wellbeing as a key component of next generation green buildings. Paper presented at the Rethinking Sustainable Construction'06 Conference, Sarasota, Florida, USA 2006

14 Wahl, Daniel Christian, and Seaton Baxter. “The designer's role in facilitating sustainable solutions.” Design Issues 24, no. 2 (2008): 72-83.

15 ibid

16 Pedersen Zari, Maibritt. "Changes in Climate Driving Changes in Architectural Education.” Enquiry: A Journal for Architectural Research 6, no. 12009

17 Cortese, Anthony D. “The critical role of higher education in creating a sustainable future." Planning for higher education 31, no. 3 (2003): 15-22.

18 ibid

19 Clegg, S., Walter P. Jarvis \& Tyrone S. Pitsis, “Making strategy matter: Social theory, knowledge interests and business education”, Business History Special Issue: The Age of Strategy: Strategy, Organizations and Society. Volume 55, Issue 7, 2013

20 Biesta, G, "What's the Point of Lifelong Learning if Lifelong Learning Has No Point? On the Democratic Deficit of Policies for Lifelong Learning", European Educational Research Journal, Volume 5, Numbers 3 \& 4, 2006

21 ibid

22 Beach, R., Lundell, D.B., \& Jung, Developmental college students' negotiation of social practices between peer, family, workplace, and university worlds. In D. B. Lundell \&J. L. Higbee (Eds.), Exploring urban literacy \& developmental education (pp. 79-108). Minneapolis, MN: Centre for Research on Developmental Education and Urban Literacy, General College, University of Minnesota 2002.

23 UNESCO (1998), World Declaration on Higher Education for the Twenty-first Century: Vision and Action, adopted by the World Conference on Higher Education 9 October. accessed 16 April 2014 http://www.unesco.org/education/educprog/wche/declaration_eng.htm 